\title{
Bufalin and 5-fluorouracil synergistically induce apoptosis in colorectal cancer cells
}

\author{
XIAO-YU DAI ${ }^{1}$, BAO-FENG ZHOU ${ }^{1}$, YANG-YANG XIE ${ }^{1}, \mathrm{JIE} \mathrm{LOU}^{2}$ and KE-QIANG LI ${ }^{3}$ \\ Departments of ${ }^{1}$ Anorectal Surgery and ${ }^{2}$ Digestion; ${ }^{3}$ Key Laboratory of Molecular Biology of Cancer, \\ Clinical Research Center, Ningbo No. 2 Hospital, Ningbo, Zhejiang 315010, P.R. China
}

Received January 6, 2016; Accepted October 18, 2017

DOI: $10.3892 / \mathrm{ol} .2018 .8332$

\begin{abstract}
FU) has been used in the treatment of colorectal cancer for $>50$ years. However, drug resistance remains an obstacle in the application of 5-FU-based chemotherapy. Bufalin, a type of steroid with anti-tumor activity, may be purified from the skin and parotid venom glands of toads. In order to improve the anti-tumor effect of 5-FU, the present study examined the combined effects of bufalin with 5-FU on human colorectal cancer HCT116 cells. Following treatment, cell proliferation was quantified using MTT assay and apoptotic cell percentage was assessed by flow cytometry. The apoptosis-associated protein expression was evaluated by western blotting. It was observed that bufalin enhanced the cytotoxicity of 5-FU in HCT116 cells via the induction of the mitochondrial apoptotic pathway. Additionally, bufalin combined with 5-FU reduced the expression levels of anti-apoptotic proteins, such as Mcl-1, XIAP and Bcl-2 and upregulated the levels of the pro-apoptotic proteins, Bax and Bad. To verify the role of Bax, RNA interference was used to knock-down Bax. It was determined that the synergistic effect between 5-FU and bufalin was diminished following the silencing of Bax. In summary, bufalin in combination with 5-FU may induce a higher level of apoptosis compared with monotherapy, and the combination mat be a potential therapeutic strategy for the treatment of colorectal cancer.
\end{abstract}

\section{Introduction}

Colorectal cancer (CRC) is considered to be one of the major causes of cancer-associated mortality worldwide (1). This

Correspondence to: Dr Xiao-Yu Dai, Department of Anorectal Surgery, Clinical Research Center, Ningbo No. 2 Hospital, 41 Xibei Road, Ningbo, Zhejiang 315010, P.R. China

E-mail: daixiaoyu0106@126.com

Dr Ke-Qiang Li, Key Laboratory of Molecular Biology of Cancer, Clinical Research Center, Ningbo No. 2 Hospital, 41 Xibei Road, Ningbo, Zhejiang 315010, P.R. China

E-mail: likeqiang1264@163.com

Key words: colorectal cancer, 5-fluorouracil, bufalin, apoptosis, B-cell lymphoma-2-associated X protein disease accounts for $9.7 \%$ of all cancer mortalities and is the most commonly diagnosed cancer subsequent to lung and female breast cancer (2). Contemporary treatment for CRC primarily relies on surgical measures and chemotherapy (3). The use of 5-fluorouracil (5-FU) has been the cornerstone of treating CRC for $>50$ years. 5-FU, a pyrimidine analog, is converted to fluorodeoxyuridine monophosphate (FdUMP) to exert its anti-tumor effect (4). FdUMP is incorporated into DNA and RNA, resulting in defective synthesis and subsequent cell apoptosis. However, toxicity that develops at high doses and drug resistance remain obstacles in the application of 5-FU (4). Over previous years, numerous efforts have been made to identify the mechanism of resistance to 5-FU. A number of studies indicated that evading of apoptosis serves an important role in the resistance to 5-FU (5-7).

Apoptosis is programmed cell death required for maintaining the balance between cell death and proliferation. There are two primary pathways that lead to the activation of apoptosis: The extrinsic pathway and the intrinsic pathway, which is also termed the mitochondrial pathway (6). The extrinsic pathway is triggered by several ligands of various death receptors. Stimuli such as cellular stress, radiation and chemotherapeutic agents may activate the intrinsic/mitochondrial pathway (8). The intrinsic pathway involves the release of mitochondrial intermembrane space proteins including cytochrome $c$ and Direct IAP-binding protein with low pI (Smac/Diablo) from the mitochondria to the cytosol (9). Cytochrome $c$ forms a multi-protein complex with apoptotic protease activating factor 1 (Apaf-1) and deoxyadenosine triphosphate termed the apoptosome, which in turn promotes the caspase cascade through cleavage of procaspase- 9 into caspase- 9 and subsequently caspase- 3 activation (10). Caspase-3 functions as the executioner caspase, by cleaving various substrates including poly adenosine 5'-diphosphate-ribose polymerase (PARP) and ultimately leading to morphological and biochemical changes in apoptotic cells (8). The intrinsic pathway is primarily regulated by the B-cell lymphoma $2(\mathrm{Bcl}-2)$ family proteins. According to their roles in the process of apoptosis, the Bcl-2 members may be additionally classified into pro-apoptotic members and anti-apoptotic members. Overexpression of anti-apoptotic Bcl-2 proteins may often induce insensitivity in cancer cells to various chemotherapeutic agents; therefore, these proteins are vital targets for the development of novel cancer therapeutics (11). 
Combined therapy, in which another agent is used simultaneously with 5-FU, may improve outcomes. 5-Fluorouracil (5-FU) used in combination with other agents such as curcumin, resveratrol and oxaliplatin may enhance the response rate and reduce the unfavorable side effects of these agents (12-14). These data suggest that 5-FU, when administered in combination with other anti-tumor agents, may result in improved treatment response when compared with 5-FU treatment alone. Bufalin, a traditional Chinese medicine also termed Huachansu, is one type of steroid that may be purified from the skin and parotid venom glands of toads (Bufo gargarizans or B. melanostictus) (15). Bufalin exhibits a significant anti-tumor effect in a variety of tumors, including hepatocellular and colorectal cancer, leukemia and gastric cancer (15-17). However, additional investigation concerning the chemo-sensitization effect of bufalin is required.

In the present study, the combined anti-tumor effect of 5-FU with bufalin on HCT116 human colorectal cancer cells was investigated. It was identified that bufalin, with 5-FU, may synergistically induce apoptosis through a mechanism involving mitochondrial apoptotic pathway activation, which depends on Bcl-2-associated X protein (Bax). The results of the present study provide the rationale for the additional evaluation of the combination of 5-FU/bufalin in human colorectal carcinoma treatment.

\section{Materials and methods}

Reagents and antibodies. Bufalin was purchased from Sigma-Aldrich (Merck KGaA, Darmstadt, Germany) and initially dissolved in anhydrous alcohol at a stock concentration of $20 \mathrm{mg} / \mathrm{ml}$ and stored at $-20^{\circ} \mathrm{C}$. The bufalin stock solution was freshly diluted to 10,20 and $30 \mu \mathrm{M}$ in the medium prior to use. 5-FU was purchased from Shanghai Xudong Haipu Pharmaceutical Co. (Shanghai, China). The propidium iodide (PI)/Annexin V staining assay kit was obtained from BD Biosciences (San Jose, CA, USA). All other chemicals used were of analytical grade and were purchased from Sigma-Aldrich (Merck KGaA). Antibodies against Bax (cat. no., sc-23959) were obtained from Santa Cruz Biotechnology, Inc. (Dallas, TX, USA). Antibodies against poly adenosine 5 '-diphosphate-ribose polymerase (PARP) (cat. no., 9532), induced myeloid leukemia cell differentiation protein Mcl-1 (Mcl-1; cat. no., 94296), X-linked inhibitor of apoptosis protein (XIAP; cat. no., 2045), B-cell lymphoma 2 (Bcl-2; cat. no., 4223), survivin, Bcl-2-like protein 4 (Bax; cat. no., 5023), Bcl-2-associated death promotor (Bad; cat. no., cat:9239), BCl-2 homologous antagonist/killer (Bak; cat. no., 6947) and $\beta$-actin (cat. no., 3700) were purchased from Cell Signaling Technology, Inc. (Danvers, MA, USA). RPMI-1640 medium and 10\% fetal bovine serum (FBS) were purchased from HyClone (GE Healthcare Life Sciences, Logan, UT, USA). Transfection Reagent Lipofectamine ${ }^{\circledR}$ 2,000 was purchased from Thermo Fisher Scientific, Inc., (Waltham, MA, USA).

Cell culture. The HCT116 human colorectal cancer cell line used was purchased from Cell Bank of Type Culture Collection of Chinese Academy of Sciences (Shanghai, China), and cultured in RPMI-1640 medium supplemented with $10 \%$ fetal bovine serum, penicillin $(100 \mathrm{U} / \mathrm{ml})$, and streptomycin $(100 \mathrm{~g} / \mathrm{ml})$ (all from Hyclone; GE Healthcare Life Sciences) at $37^{\circ} \mathrm{C}$ in a $5 \% \mathrm{CO}_{2}$ humidified atmosphere. Cells were maintained as a monolayer and sub-cultured every 3 days. Cells were used when the monolayer reached $70 \%$ confluence for all experiments.

MTT viability assay. HCT116 cells were seeded in 96-well plates at $1 \times 10^{4}$ cells/well for $12 \mathrm{~h}$, and then incubated at $37^{\circ} \mathrm{C}$ in the presence various concentrations of 5-FU $(5,10$ or $15 \mu \mathrm{M})$ with or without different concentrations of bufalin $(10,20$ or $30 \mathrm{nM}$ ) for $24 \mathrm{~h}$. Following this, $20 \mu \mathrm{l}$ MTT solution $(5 \mathrm{mg} / \mathrm{ml}$ in PBS, $\mathrm{pH}$ 7.2) was added to each well and the plates were incubated at $37^{\circ} \mathrm{C}$ for $4 \mathrm{~h}$. Subsequent to removing the medium containing MTT, $150 \mu \mathrm{l}$ dimethyl sulfoxide was added to each well. The plates were incubated at room temperature on a plate shaker for $10 \mathrm{~min}$, and absorbance at $570 \mathrm{~nm}$ was measured using a Bio-Rad 680 microplate reader (Bio-Rad Laboratories, Inc., Hercules, CA, USA). Each experiment was conducted in triplicate.

Apoptosis analysis. To detect apoptosis, cells were incubated with 5-FU $(15 \mu \mathrm{M})$ with or without bufalin $(30 \mathrm{nM})$ for $24 \mathrm{~h}$ at $37^{\circ} \mathrm{C}$. The cells were harvested, washed twice with cold 1X PBS, and re-suspended in $200 \mu \mathrm{l}$ binding buffer at density of $1 \times 10^{5}$ cells $/ \mathrm{ml}$. The cells were then stained with $5 \mu \mathrm{l}$ Annexin-V and PI (BD Biosciences) for $20 \mathrm{~min}$ in the dark at room temperature, and subjected to analysis by flow cytometry (FACScan, BD Biosciences, Franklin Lakes, NJ, USA). Apoptosis was evaluated based on the percentage of cells with Annexin V+/PI+ staining. The results were presented as mean values from three independent experiments. The results were analyzed by FlowJo 10.0.5 (Tree Star, Inc., Ashland, OR, USA) software.

RNA interference. On-target Bax and scramble small interfering (si)RNA were purchased from Guangzhou RiboBio Co., Ltd (Guangzhou, China). Bax and scramble small interfering (si)RNA were transfected to the cells with Lipofectamine ${ }^{\circledR}$ 2000 (Invitrogen; Thermo Fisher Scientific, Inc.) in accordance with the manufacturer's protocol. Downregulation of the protein was confirmed by immunoblotting $24 \mathrm{~h}$ following transfection.

Immunoblotting and immunoprecipitation. Cells were separately washed, collected and homogenized in a lysis buffer (10 mM Tris-HCl, pH 8, $0.32 \mathrm{mM}$ sucrose, $5 \mathrm{mM}$ EDTA, $2 \mathrm{mM}$ dithiothreitol, $1 \mathrm{mM}$ phenylmethyl sulfonylfluoride, and $1 \%$ Triton $\mathrm{X}-100)$, and centrifuged $(13,000 \mathrm{x} \mathrm{g}$ for $10 \mathrm{~min}$ at $\left.4^{\circ} \mathrm{C}\right)$. Equal amounts of proteins $(50 \mu \mathrm{g})$ were subjected to electrophoresis in a 10\% SDS-PAGE gel. The gel-separated proteins were transferred to Nitropure ${ }^{\mathrm{TM}}$ nitrocellulose membranes (Santa Cruz Biotechnology, Inc.) and the membranes were blocked with $10 \%$ fat-free milk in TBST overnight at $4^{\circ} \mathrm{C}$ and probed with primary antibodies $(1: 1,000)$ at $37^{\circ} \mathrm{C}$ for $2 \mathrm{~h}$. Each of the targeted proteins was immunostained by specific antibodies. The membranes were washed three times with TBST and then incubated for $1 \mathrm{~h}$ at room temperature with alkaline phosphatase-conjugated 
bovine anti-rabbit (cat no., sc-2379) or goat anti-mouse (cat no., sc-2039) secondary antibodies (both 1:5,000; Santa Cruz Biotechnology, Inc.). Finally, the protein bands were visualized by enhanced chemiluminescent reagents (Thermo Fisher Scientific., Inc.). Equal amounts of protein from cell lysates $(600 \mu \mathrm{g})$ were used for Bax immunoprecipitation. All samples were brought to a final volume of $450 \mu \mathrm{l}$ with cellular lysis buffer. Samples were then rotated for $5 \mathrm{~h}$ at $4^{\circ} \mathrm{C}$ with $5 \mu 1$ of monoclonal antibodies (BAX 6A7) and $150 \mu 1$ anti-rabbit IgG magnetic beads (ready-to-use dilution; cat. no., 11203D; Thermo Fisher Scientific., Inc.). Then, the supernatants from the beads were precipitated by a magnetic field. The beads were then washed five times with the cellular lysis buffer. Finally, the last supernatant was removed and $25 \mu \mathrm{l}$ of 5X SDS-PAGE loading buffer (cat. no., P0015; Beyotime Institute of Biotechnology, Haimen, China) was added. The beads were incubated in the loading buffer at $95-100^{\circ} \mathrm{C}$ for $5 \mathrm{~min}$, and then centrifuged at $13,400 \mathrm{x}$ g for $5 \mathrm{~min}$ at $4^{\circ} \mathrm{C}$. The supernatants were subjected to immunoblotting analysis as aforementioned. Proteins were detected by the Pierce ${ }^{\mathrm{TM}}$ ECL Western Blotting Substrate (Thermo Fisher Scientific, Inc.) and visualized by the Image $\mathrm{Lab}^{\mathrm{TM}}$ software, version 6.0 on the Molecular Imager Gel Doc XR+ System (Bio-Rad Laboratories, Inc., Hercules, CA, USA).

Preparation of subcellular fractions. In order to separate the cytosolic and mitochondria fractions, cells were washed three times in ice-cold PBS. The cells were then lysed using Cell Lysis and Mitochondria Intact buffer (cat. no., P3102; Beyotime Institute of Biotechnology) on ice for $5 \mathrm{~min}$ and the cell suspensions were centrifuged at $401 \mathrm{x} \mathrm{g}$ for $5 \mathrm{~min}$ at $4^{\circ} \mathrm{C}$. The supernatant was removed and stored at $-20^{\circ} \mathrm{C}$ as the cytosolic fraction.

Statistical analysis. Data are presented as the mean \pm standard deviation. Differences between groups were compared using one-way analysis of variance followed by the Fisher's Least Significant Difference test. Statistical analysis was performed using SPSS, version 17.0 (SPSS, Inc., Chicago, IL, USA), and $\mathrm{P}<0.05$ was considered to indicate a statistically significant difference. The half maximal inhibitory concentration $\left(\mathrm{IC}_{50}\right)$ and combined effect of 5-FU and bufalin was evaluated using CompuSyn 2.0 software (ComboSyn Inc., New York, NY, USA). This method of analysis generally defines the combination as positive (synergistic) when the combination index (CI) is $<0.9$, negative (antagonistic) when the CI is $>1.1$, or additive when the CI is from 0.9 to 1.1 .

\section{Results}

Effects of 5-FU, bufalin and combinations on viability of HCT116 cells. The chemical structure of bufalin is presented in Fig. 1. The cytotoxic effects of 5-FU, bufalin and their combination treatment effect on the HCT116 human colorectal cancer cell line were evaluated. Firstly, cells were treated for $24 \mathrm{~h}$ with various concentrations of 5 -FU $(5,10$ or $15 \mu \mathrm{M})$ and/or bufalin $(0.01,0.02,0.03 \mu \mathrm{M})$ (Fig. 2A). The cell viability was evaluated using an MTT assay. The $\mathrm{IC}_{50}$ levels of 5-FU and bufalin were $28.01 \pm 0.91 \mu \mathrm{M}$ and $58.03 \pm 3 \mathrm{nM}$, respectively. Cells were subsequently treated with a constant concentration
Table I. CI analysis of 5-FU with bufalin in HCT116 cells.

\begin{tabular}{lcc}
\hline $5-\mathrm{FU}(\mu \mathrm{M})$ & Bufalin $(\mu \mathrm{M})$ & $\mathrm{CI}$ \\
\hline 5.0 & 0.01 & 0.82295 \\
& 0.02 & 0.81846 \\
& 0.03 & 0.78597 \\
10.0 & 0.01 & 0.76462 \\
& 0.02 & 0.75372 \\
& 0.03 & 0.75132 \\
15.0 & 0.01 & 0.86689 \\
& 0.02 & 0.77369 \\
& 0.03 & 0.54867 \\
\hline
\end{tabular}

5-FU, 5-fluorouracil; CI, combination index; $\mathrm{CI}=1$, additive; $\mathrm{CI}<1$, synergistic; $\mathrm{C}>1$, antagonistic.

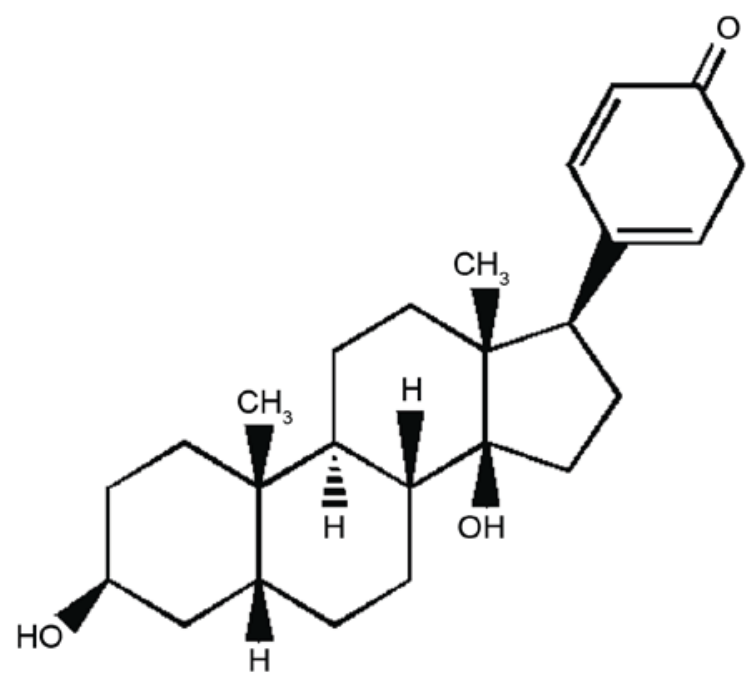

Figure 1. Chemical structure of bufalin.

of 5-FU $(10 \mu \mathrm{M})$ and/or bufalin $(0.01 \mu \mathrm{M})$ for 24,36 and $48 \mathrm{~h}$ (Fig. 2B). It was determined that 5-FU and bufalin inhibited the viability of HCT116 cells in dose- and time- dependent manners, and their combination demonstrated a more marked inhibitory effect compared with the single agent (Fig. 2). Then, the CompuSyn software was used to calculate the CI values, as summarized in Table I. The present study indicated that 5-FU's ability to affect the viability of HCT116 cells was additionally enhanced when the drug was combined with bufalin. Based on CI values, the present study selected the combination of $15 \mu \mathrm{M} 5$-FU and $0.03 \mu \mathrm{M}$ bufalin for subsequent experiments $(\mathrm{CI}=0.54867)$.

Bufalin sensitizes 5-FU-induced apoptosis in HCT116 cells. To elucidate how bufalin and 5-FU exert their synergistic anti-tumor effects on HCT 116 cells, specifically whether the combined therapy induced apoptosis. The level of apoptosis was measured by Annexin V/PI staining and flow cytometry. The results demonstrated that combined treatment of 5-FU with bufalin significantly increased the percentage of apoptotic cells compared with 5-FU or bufalin alone for 


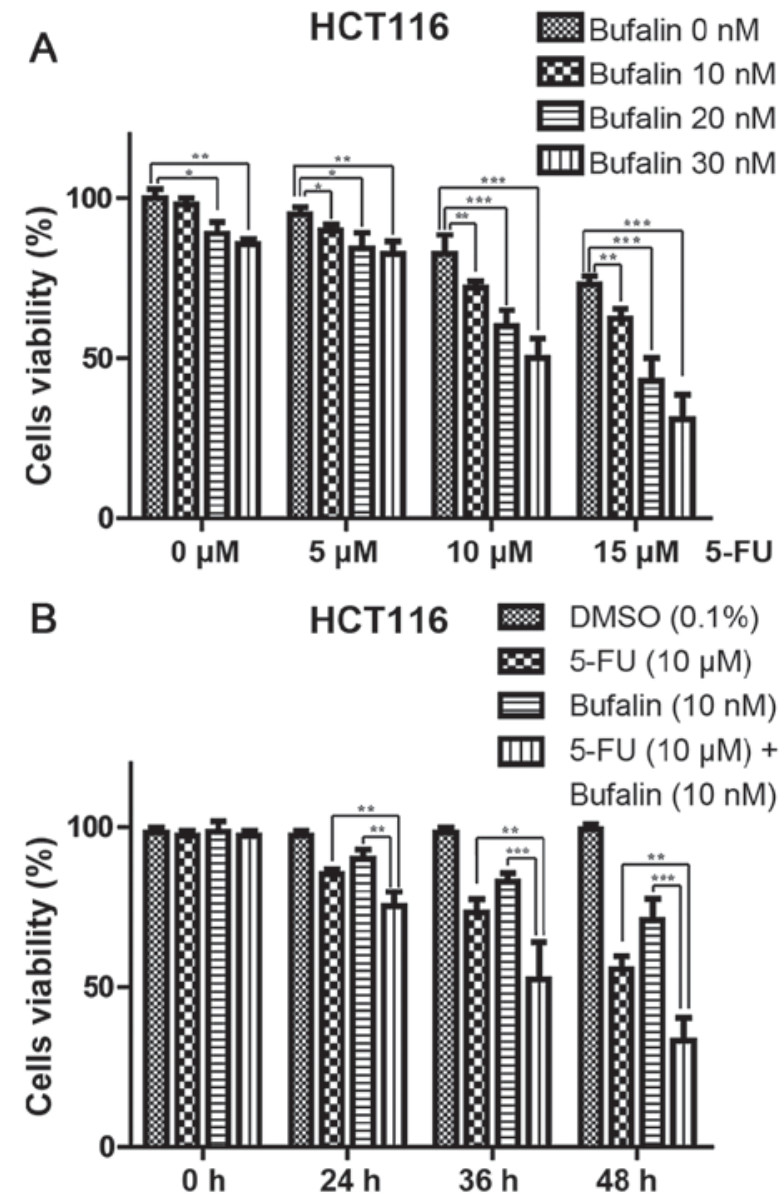

Figure 2. Bufalin and 5-FU synergistically inhibits the proliferation of HCT116 cells in a dose- and time-dependent manner. (A) Percentage of viable cells following single and co-treatment of various concentrations of bufalin for $24 \mathrm{~h}$. (B) Percentage of viable cells following single and co-treatment of constant concentrations of bufalin $(10 \mathrm{nM})$ and 5-FU $(10 \mu \mathrm{M})$ for the indicated times. Values are expressed as the mean \pm standard deviation. ${ }^{*} \mathrm{P}<0.05$, ${ }^{* *} \mathrm{P}<0.01$ and ${ }^{* * * *} \mathrm{P}<0.001,5-\mathrm{FU}, 5$-fluorouracil.

$24 \mathrm{~h}$ (Fig. 3A and B). To additionally investigate the mechanism behind apoptosis, the activation of caspases, namely caspase- 9 and caspase-3, was quantified using western blotting. As demonstrated in Fig. 3C, the levels of the activated caspase- 3 and caspase- 9 fragments were higher in the cells treated with the combined treatment compared with the single agent-treated cells. The cleaved PARP was also increased in the cells with co-treatment. These data indicate that 5-FU/bufalin-induced apoptosis may occur via the mitochondrial pathway in HCT116 cells.

Bufalin and 5-FU synergistically induce apoptosis in HCT116 cells via mitochondrial pathway. The members of the Bcl-2 family have important roles in regulating the process of apoptosis. Therefore, whether the combined treatment with bufalin and 5-FU induced apoptosis via altering the levels of the apoptosis-associated members of this family was examined. Compared with the control and single agent-treated group, co-treatment with 5-FU and bufalin decreased the expression of Mcl-1, Bcl-2, XIAP, while it upregulated the expression of Bax and Bad (Fig. 4A). Concurrently, the expression of Bak was not affected (Fig. 4A). Additionally, a specific Bax antibody
(6A7) was used to detect the status of Bax. As demonstrated in Fig. 4B, Bax was activated following the combined treatment of 5-FU/bufalin. In addition, the release of mitochondrial proteins cytochrome $c$ and Smac/Diablo into the cytosol was significantly increased following the combined treatment of 5-FU and bufalin (Fig. 4C). Therefore, this implies that 5-FU/bufalin-induced apoptosis occurs primarily through the mitochondrial apoptotic pathway.

Upregulation of Bax is required for the induction of apoptosis by co-treatment of 5-FU and bufalin. As it was observed that Bax was activated by the combinational treatment of 5-FU and bufalin (Fig. 4A), the present study aimed to determine whether the apoptosis induced by 5 -FU/bufalin was dependent on Bax. In order to examine this, Bax or scramble siRNA were transfected into cells, followed by treatment with 5-FU/bufalin (Fig. 5). The level of apoptosis induced by $5-\mathrm{FU} /$ bufalin was significantly attenuated in cells with silencing of Bax compared with the cells transfected with scramble siRNA (Fig. 5A and C). In addition, the western blotting assay indicated that following treatment with 5-FU/bufalin, cleaved caspase-3, caspase-9 and PARP were also attenuated by knockdown of Bax (Fig. 5B). These findings indicated that 5-FU/bufalin-triggered apoptosis relied on the activation of Bax in HCT116 cells.

\section{Discussion}

Resistance to 5-FU treatment is one of the major causes for the failure of chemotherapy in treating advanced colorectal cancer (4). Therefore, it is vital to develop novel strategies to increase the effectiveness of 5-FU for therapeutic purposes. Combination therapy via the simultaneous administration of various therapeutic agents has emerged as a crucial strategy for achieving enhanced anti-tumor activity through synergistic effects. In the present study, it was observed that combined 5-FU and bufalin treatment had a synergistic anti-tumor effect against human colorectal cancer cells $(\mathrm{CI}<1$; Table I).

5-FU exerts its anti-tumor effect by blocking cell cycle progression, inducing DNA damage, which leads to cellular apoptosis (4). Previous studies have indicated that extracts from Chinese traditional medicine may increase the cytotoxicity of 5-FU against colorectal cancer cells such as resveratrol, curcumin and ginsenoside $(12,18,19)$. Bufalin, a major immunoreactive component of the skin and parotid venom gland of toads, exhibits a variety of effects, including cardiotonic, anesthetic, blood pressure stimulation, respiration and antineoplastic (15). Previous studies have suggested that bufalin may induce growth inhibition, cell cycle arrest and cellular apoptosis in various tumor cells (20-22). In addition, bufalin may interfere with the differentiation and proliferation of cancer stem cells derived from primary osteosarcoma cells (23). Bufalin also inhibits epithelial-to-mesenchymal transition and migration by downregulating TGF- $\beta$ receptors in human lung cancer cells (24).

In the present study, it was observed that combined treatment with 5-FU and bufalin was more effective compared with monotherapy with $5-\mathrm{FU}$ or bufalin alone in the inhibition of HCT116 cell proliferation (Fig. 2). Based 


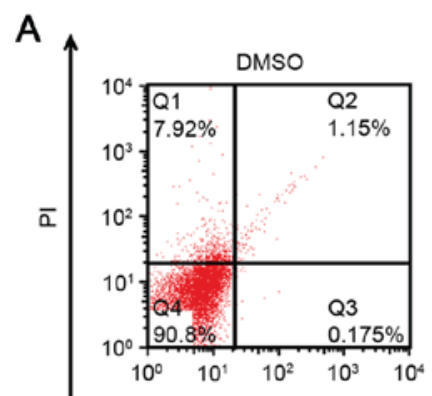

B

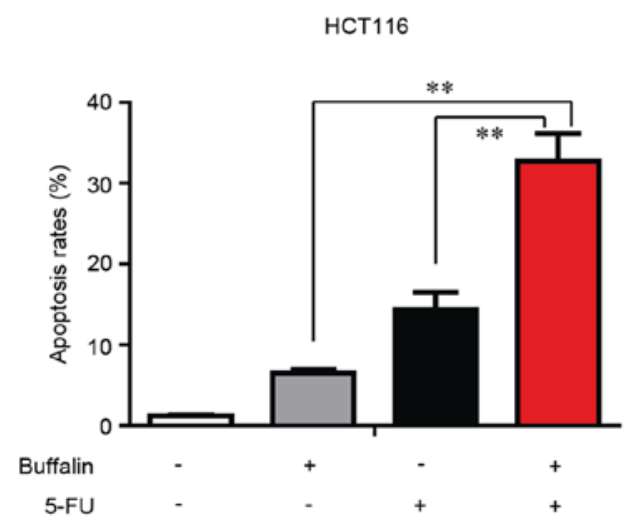

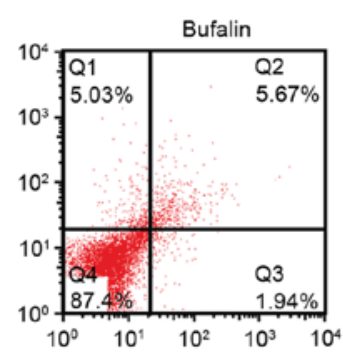
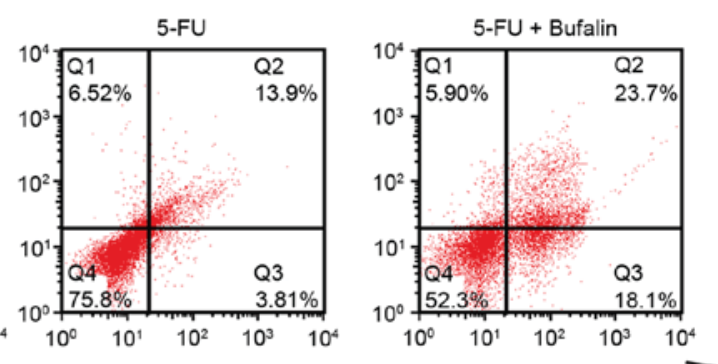

Annexin V-FITC

C

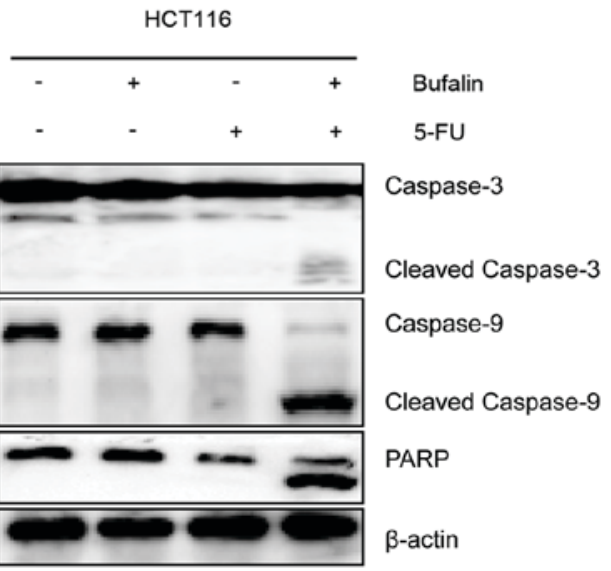

Figure 3. Bufalin and 5-FU synergistically induces apoptosis in HCT116 cells. HCT116 cells were treated with 5-FU, bufalin only, or in combination for 24 h. (A) Representative flow cytometry profiles of apoptosis. (B) Quantitative results obtained using Annexin V/PI staining. (C) Protein expression levels of caspase-9, caspase-3, PARP were quantified by western blotting. The level of $\beta$-actin was used as the loading control. ${ }^{* *} \mathrm{P}<0.01$. Data are presented as means \pm standard deviation of triplicate samples. 5-FU, 5-fluorouracil; PI, propidium iodide; FITC, fluorescein isothiocyanate; PARP, poly adenosine 5'-diphosphate-ribose polymerase.

A

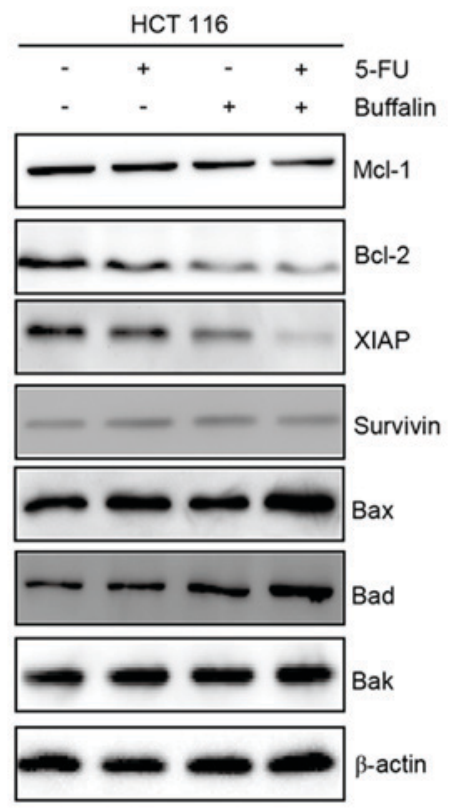

B

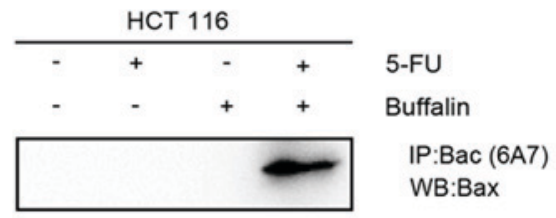

C

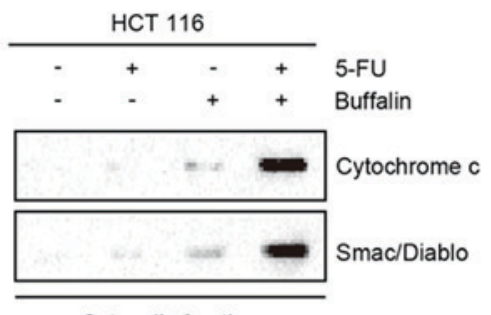

Cytosolic fraction

Figure 4. Effects of 5-FU and bufalin on apoptosis-associated proteins in HCT116 cells. HCT116 cells were treated with 5-FU or bufalin alone, or in a combination for 24 h. (A) Protein levels of Mcl-1, XIAP, Bcl-2, Survivin, Bax, Bad and Bak were determined by WB, $\beta$-actin was used as the loading control. (B) Bax activation was determined by IP using active conformation-specific antibody (6A7). (C) Release of cytochrome $c$ and Smac/Diablo were detected in the cytosolic fraction of cells. Data are presented as one of triplicate experiments. WB, western blotting; IP, immunoprecipitation; 5-FU, 5-fluorouracil; Bcl-2, B-cell lymphoma 2; Mcl-1, induced myeloid leukemia cell differentiation protein Mcl-1; XIAP, X-linked inhibitor of apoptosis protein; Bax, Bcl-2-like protein 4; Bad, Bcl-2-associated death promotor; Bak, Bcl-2 homologous antagonist killer. 
A

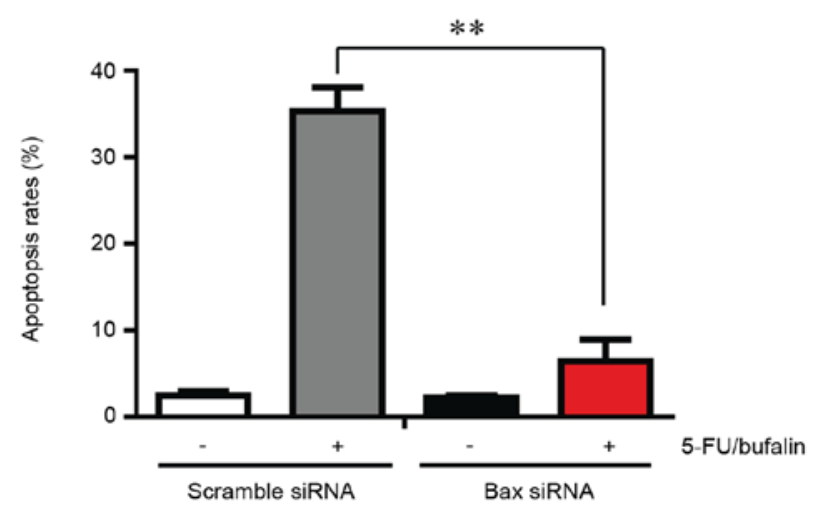

C

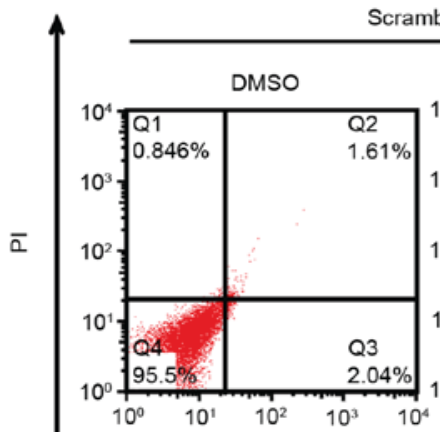

B

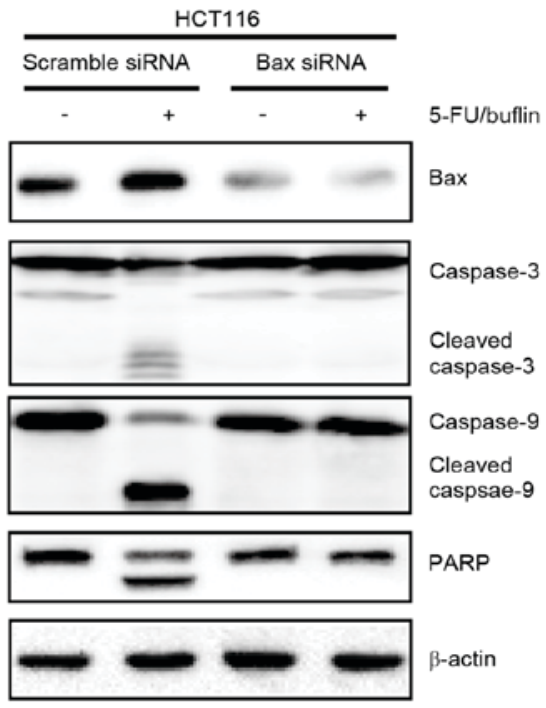

Bax siRNA

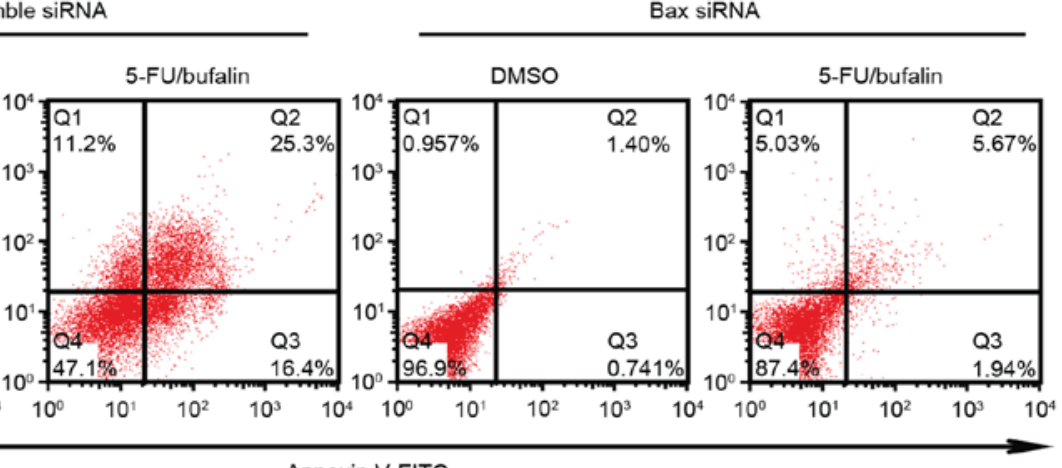

Annexin V-FITC

Figure 5. Bax is required for the apoptosis induced by 5-FU and bufalin. HCT116 cells were transfected with Bax siRNA or scramble siRNA and then treated with or without 5-FU/bufalin for 24 h. (A) Quantitative results obtained using Annexin V/PI staining. (B) Protein levels of Bax, caspase-3, caspase-9 and PARP were detected by western blotting. $\beta$-actin was used as the loading control. (C) Representative flow cytometry profiles of apoptosis following treatment. ${ }^{* *} \mathrm{P}<0.01$. Data are presented as means \pm standard deviation of triplicate experiments. 5-FU, 5-fluorouracil; Bax, B-cell lymphoma-2-like protein 4; PARP, poly adenosine 5'-diphosphate-ribose polymerase; siRNA, small interfering RNA; PI, propidium iodide; FITC, fluorescein isothiocyanate.

on these findings, the present study investigated whether the enhanced anti-tumor effects of combined treatment were caused by their effects on cell apoptosis. Apoptosis is primarily mediated through the extrinsic and/or intrinsic pathway: In previous studies, chemotherapeutic agents such as 5-FU induced apoptosis primarily through the intrinsic pathway $(4,25)$. Conversely, bufalin was able to trigger apoptosis through either extrinsic and/or intrinsic pathways (26). In order to clarify through which pathway 5-FU/bufalin induces apoptosis, the activation of caspases was investigated and it was identified that caspase- 9 activation was significantly increased following the combined treatment of 5-FU and bufalin (Fig. 3C). Activation of caspase-3 and cleaving of PARP are hallmarks of apoptosis that lead to DNA fragmentation and subsequently cell death. Therefore, 5-FU/bufalin induced apoptosis via the caspase-9-caspase-3 axis in HCT116 cells.

The present study revealed the downregulation of anti-apoptotic protein $\mathrm{Bcl}-2$ with a concomitant upregulation of Bax, Bad and activation of Bax (Fig. 4A and B). In previous studies, downregulation of Bax contributed to colorectal carcinogenesis and resistance to 5-FU and increase in the expression of Bax enhanced the susceptibility to 5-FU $(23,24)$. Subsequent to silencing of Bax, it was also observed that the apoptosis induced by 5-FU/bufalin and the cleavage of caspase-3, -9, PARP was reduced (Fig. 5A and B). All these findings highlight the critical role of $\mathrm{Bax}$ in regulating the cellular response to 5-FU. An additional pro-apoptotic Bcl-2 member Bad promoted apoptosis through antagonizing the anti-apoptotic role of Bcl-2 (27). The upregulation of Bax and $\mathrm{Bad}$, and the downregulation of Bcl-2 may lead to an increase of the $\mathrm{Bax} / \mathrm{Bcl}-2$ ratio which will lead to the permeabilization of outer mitochondrial membrane, resulting in the release of mitochondrial proteins such as cytochrome $c$ and/or Smac/Diablo (9). The present study was also able to detect the release of cytochrome $c$ and Smac/Diablo in the cytosolic fraction of cells following co-treatment (Fig. 4C). Cytochrome $c$ forms a complex termed the apoptosome with Apaf- 1 and procaspase-9. Procaspase-9 may be self-activated within the apoptosome, resulting in the activation of downstream caspases including caspase-3. However, this process may be blocked by XIAP through binding to and inhibiting caspase- 3 and caspase-9 (9). The present study observed that XIAP was also downregulated following the combined treatment of 
5-FU and bufalin (Fig. 4A). The release of Smac/Diablo in the cytosol also blocked the anti-apoptotic activity of XIAP by preventing it from binding to caspase-3 (8). XIAP also confers resistance to other anti-tumor agents such as TRAIL, doxorubicin and cisplatin $(6,28)$. Additionally, XIAP has also been implicated in the process of metastasis, making it a viable potential target for cancer therapy (29). Therefore, the effects of 5-FU/bufalin on the metastatic properties of colorectal cancer cells should be investigated further.

In conclusion, 5-FU and bufalin cooperated to promote apoptosis via the intrinsic pathway, and Bax is required for the synergistic effect. Although there are multiple studies concerning 5-FU or bufalin in inhibition of tumors, the anti-tumor effects of the two agents in combination remain to be elucidated. Previous studies investigating chemotherapeutics suggested that traditional chemotherapy agents are not capable of eradicating cancer stem cells (CSCs) and do not to prevent disease relapse, indicating that novel strategies should focus on the capability to target CSCs (7). Bufalin, which has already been demonstrated to be relatively safe in clinical trials (30), also possesses the ability to inhibit the differentiation and proliferation of CSCs $(23,31)$. The data of the present study may have important clinical implications for the treatment and prevention of colon cancer.

\section{Acknowledgements}

Not applicable.

\section{Funding}

The present study was supported by grants from the Natural Science Foundation of Ningbo (grant no. 2014A610225), Medical Foundation of Ningbo (grant no. 211B10), Social Development and Scientific and Technological Projects Foundation of Ningbo (grant no. 2014C50068), Huamei Foundation of Ningbo No. 2 Hospital (grant nos. 2015HMKY07, 2015HMKY08 and 2015HMKY36).

\section{Availability of data and materials}

The datasets used and/or analyzed during the current study are available from the corresponding author on reasonable request.

\section{Author's contributions}

XD was involved in the planning of the article, provided experimental guidance and cultivated the colon cancer cells. BZ conducted cell culture and drug treatment experiments. KL analyzed the data and wrote the paper. JL conducted apoptotic analysis. YX detected protein expression alterations in the cells.

\section{Ethics approval and consent to participate}

Not applicable.

\section{Consent for publication}

Not applicable.

\section{Competing interests}

The authors declare that they have no competing interests.

\section{References}

1. Siegel RL, Miller KD and Jemal A: Cancer statistics, 2016. CA Cancer J Clin 66: 7-30, 2016.

2. Torre LA, Siegel RL, Ward EM and Jemal A: Global cancer incidence and mortality rates and trends-an update. Cancer Epidemiol Biomarkers Prev 25: 16-27, 2016.

3. Mayer RJ: Targeted therapy for advanced colorectal cancer-more is not always better. N Engl J Med 360: 623-625, 2009.

4. Longley DB, Harkin DP and Johnston PG: 5-fluorouracil: Mechanisms of action and clinical strategies. Nat Rev Cancer 3: 330-338, 2003.

5. Temraz S, Mukherji D, Alameddine R and Shamseddine A: Methods of overcoming treatment resistance in colorectal cancer. Crit Rev Oncol Hematol 89: 217-230, 2014.

6. Yu R, Deedigan L, Albarenque SM, Mohr A and Zwacka RM: Delivery of sTRAIL variants by MSCs in combination with cytotoxic drug treatment leads to p53-independent enhanced antitumor effects. Cell Death Dis 4: e503, 2013.

7. Rich JN and Bao S: Chemotherapy and cancer stem cells. Cell Stem Cell 1: 353-355, 2007.

8. Tummers B and Green DR: Caspase-8: Regulating life and death. Immunol Rev 277: 76-89, 2017.

9. Estaquier J, Vallette F, Vayssiere JL and Mignotte B: The mitochondrial pathways of apoptosis. Adv Exp Med Biol 942: 157-183, 2012.

10. Susin SA, Lorenzo HK, Zamzami N, Marzo I, Snow BE, Brothers GM, Mangion J, Jacotot E, Costantini P, Loeffler M, et al: Molecular characterization of mitochondrial apoptosis-inducing factor. Nature 397: 441-446, 1999.

11. Azmi AS, Wang Z, Philip PA, Mohammad RM and Sarkar FH: Emerging Bcl-2 inhibitors for the treatment of cancer. Expert Opin Emerg Drugs 16: 59-70, 2011.

12. Shakibaei M, Mobasheri A, Lueders C, Busch F, Shayan P and Goel A: Curcumin enhances the effect of chemotherapy against colorectal cancer cells by inhibition of NF- $\mathrm{KB}$ and Src protein kinase signaling pathways. PLoS One 8: e57218, 2013.

13. Douillard JY, Sobrero A, Carnaghi C, Comella P, Díaz-Rubio E, Santoro A and Van Cutsem E: Metastatic colorectal cancer: Integrating irinotecan into combination and sequential chemotherapy. Ann Oncol 14 (Suppl 2): ii7-ii12, 2003.

14. Giacchetti S, Perpoint B, Zidani R, Le Bail N, Faggiuolo R, Focan C, Chollet P, Llory JF, Letourneau Y, Coudert B, et al: Phase III multicenter randomized trial of oxaliplatin added to chronomodulated fluorouracil-leucovorin as first-line treatment of metastatic colorectal cancer. J Clin Oncol 18: 136-147, 2000.

15. Lu CX, Nan KJ and Lei Y: Agents from amphibians with anticancer properties. Anticancer Drugs 19: 931-939, 2008.

16. Miao Q, Bi LL, Li X, Miao S, Zhang J, Zhang S, Yang Q, Xie YH, Zhang J and Wang SW: Anticancer effects of bufalin on human hepatocellular carcinoma HepG2 cells: Roles of apoptosis and autophagy. Int J Mol Sci 14: 1370-1382, 2013.

17. Xie CM, Chan WY, Yu S, Zhao J and Cheng CH: Bufalin induces autophagy-mediated cell death in human colon cancer cells through reactive oxygen species generation and JNK activation. Free Radic Biol Med 51: 1365-1375, 2011.

18. Santandreu FM, Valle A, Oliver J and Roca P: Resveratrol potentiates the cytotoxic oxidative stress induced by chemotherapy in human colon cancer cells. Cell Physiol Biochem 28: 219-228, 2011.

19. Fishbein AB, Wang CZ, Li XL, Mehendale SR, Sun S, Aung $\mathrm{HH}$ and Yuan CS: Asian ginseng enhances the anti-proliferative effect of 5-fluorouracil on human colorectal cancer: Comparison between white and red ginseng. Arch Pharm Res 32: 505-513, 2009.

20. Jiang L, Zhao MN, Liu TY, Wu XS, Weng H, Ding Q, Shu YJ, Bao RF, Li ML, Mu JS, et al: Bufalin induces cell cycle arrest and apoptosis in gallbladder carcinoma cells. Tumour Biol 35: 10931-10941, 2014.

21. Qiu DZ, Zhang ZJ, Wu WZ and Yang YK: Bufalin, a component in Chansu, inhibits proliferation and invasion of hepatocellular carcinoma cells. BMC Complement Altern Med 13: 185, 2013. 
22. Takai N, Ueda T, Nishida M, Nasu K and Narahara H: Bufalin induces growth inhibition, cell cycle arrest and apoptosis in human endometrial and ovarian cancer cells. Int J Mol Med 21: 637-643, 2008

23. Chang Y, Zhao Y, Gu W, Cao Y, Wang S, Pang J and Shi Y: Bufalin inhibits the differentiation and proliferation of cancer stem cells derived from primary osteosarcoma cells through Mir-148a. Cell Physiol Biochem 36: 1186-1196, 2015.

24. Zhao L, Liu S, Che X, Hou K, Ma Y, Li C, Wen T, Fan Y, $\mathrm{Hu}$ X, Liu Y and Qu X: Bufalin inhibits TGF- $\beta$-induced epithelial-to-mesenchymal transition and migration in human lung cancer A549 cells by downregulating TGF- $\beta$ receptors. Int J Mol Med 36: 645-652, 2015.

25. Sampath D, Rao VA and Plunkett W: Mechanisms of apoptosis induction by nucleoside analogs. Oncogene 22: 9063-9074, 2003

26. Hong SH and Choi YH: Bufalin induces apoptosis through activation of both the intrinsic and extrinsic pathways in human bladder cancer cells. Oncol Rep 27: 114-120, 2012.

27. Datta SR, Katsov A, Hu L, Petros A, Fesik SW, Yaffe MB and Greenberg ME: 14-3-3 proteins and survival kinases cooperate to inactivate $\mathrm{BAD}$ by $\mathrm{BH} 3$ domain phosphorylation. Mol Cell 6: 41-51, 2000.
28. Qu Y, Xia P, Zhang S, Pan S and Zhao J: Silencing XIAP suppresses osteosarcoma cell growth, and enhances the sensitivity of osteosarcoma cells to doxorubicin and cisplatin. Oncol Rep 33: 1177-1184, 2015.

29. Mehrotra S, Languino LR, Raskett CM, Mercurio AM, Dohi T and Altieri DC: IAP regulation of metastasis. Cancer Cell 17: 53-64, 2010.

30. Qi F, Li A, Inagaki Y, Kokudo N, Tamura S, Nakata M and Tang W: Antitumor activity of extracts and compounds from the skin of the toad Bufo bufo gargarizans Cantor. Int Immunopharmacol 11: 342-349, 2011.

31. Meng Z, Yang P, Shen Y, Bei W, Zhang Y, Ge Y, Newman RA, Cohen L, Liu L, Thornton B, et al: Pilot study of huachansu in patients with hepatocellular carcinoma, nonsmall-cell lung cancer, or pancreatic cancer. Cancer 115: 5309-5318, 2009. 